\title{
Kite Battle: Tradition and Acculturation
}

\author{
Chie Ikkai* \\ *Faculty of Sport Sciences, Waseda University \\ 2-579-15 Mikajima, Tokorozawa, Saitama 359-1192 Japan \\ chie@aoni.waseda.jp \\ [Received January 31, 2005 ; Accepted July 13, 2005]
}

\begin{abstract}
The kite is a toy made of a thin bamboo frame covered with paper, that you fly in the air at the end of attached long strings. One of how to play kite is trying to drop other kite by cutting the string of it. It is called "kite battle". Kite battles are popular in Japan. In this paper, I consider the tradition and the transformation of Sanjo-Ika-gassen (the Sanjo great kite battle) as one example of kite battle in Japan. Sanjo-Ika-gassen is a kite battle with big hexagon kite. It takes place on the first weekend of June In Sanjo city, Niigata Prefecture. Hexagon kite is original style of this area and can carry easily by drawing out the bone and rolling it. Therefore this style kite is called Rokkaku-Ika(hexagon kite), Maki-Ika (rollable kite), and Rokkaku-Maki-Ika (rollable hexagon kite). Participants of Sanjo-Ika-gassen have pride at the birthplace of hexagon kite as their tradition. The other hand, they are trying to transform the Sanjo-Ika-gassen into resource for tourism. Sanjo-Ika-gassen is a good example of Japanese ethnic sport aiming at coexisting of preservation and transformation of tradition.
\end{abstract}

Keywords: kite battle, hexagon kite, resource for tourism

[International Journal of Sport and Health Science Vol.4, 179-186, 2006]

\section{Introduction}

\subsection{Aim of study}

The kite is a toy framed with thin bamboos and covered with paper, to be flown in the air at the end of a long flying line attached to it. There are various theories on the origins and birth place of kites, east Asia and south-east Asia being the most likely. ${ }^{1}$ Aside from just flying a kite, there is another way to play with kites, called the "kite battle", which is a fight to force the opponent's kite to the ground by entangling or cutting the flying lines.

Kite battles are popular in Japan. There are the "Hamamatsu Festival Kite Battle" in Hamamatsu City, Shizuoka Prefecture; the "Shirone Giant Kite Battle" in Shirone City, Niigata Prefecture; and the "Ikazaki Giant Kite Battle" in Uchiko Town (formerly Ikazaki), Kita County, Ehime Prefecture. These are famous as the "three major kite battles" in Japan. There are plenty of other kite battles in Niigata and Aichi Prefectures. Among them, this study examines the Sanjo-Ika-Gassen (the Sanjo
Great Kite Battle) held in Sanjo City, Niigata Prefecture, using kites specific to this region, and reports the traditions and transitions of the event, describing the phenomena observed there.

\subsection{Method of study}

This study is based on literature documentation and on spoken statements of the people involved in Sanjo-Ika-Gassen in March and June 2000. Here all description without any notation is based on collected spoken statements.

\section{Sanjo-Ika-Gassen (the Sanjo Great Kite Battle)}

\subsection{Overview of Sanjo City}

Sanjo City is located at the center of Niigata Prefecture with an area of 79.75 square $\mathrm{km}$ and a population of 84,833 (as of Dec. 2004) ${ }^{2}$. It is a medium-sized city in the Chuetsu district, situated at the joint of a high-speed transportation network

1 Obayashi, T., et al (ed), 1998, Encyclopedia of Ethnic Play and Games, Taishukan (in Japanese) p.110

2 Sanjo City Website (http://www.city.sanjo.niigata.jp/) 


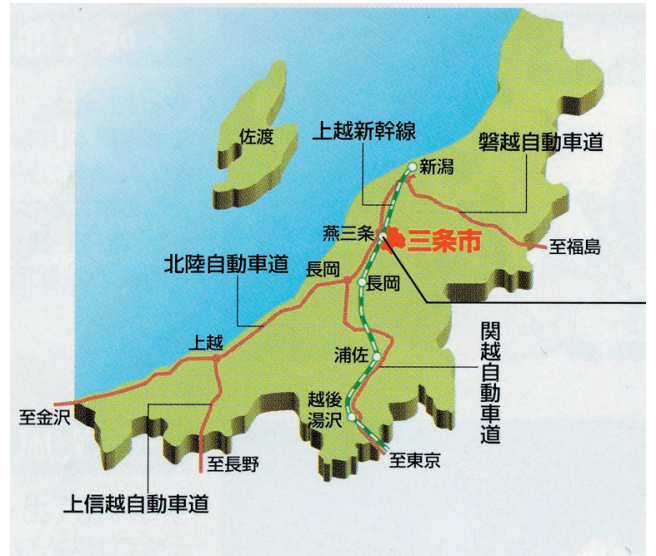

Figure 1 The site of Sanjo City from Sanjo Guide Map, Niigata, Sanjo City Chamber of Commerce and Industry 2000

including the Joetsu Shinkansen, the Hokuriku Express Way and the Kan' etsu Express Way. Sanjo City together with Tsubame City, a neighbor city to the west, are known for their metal-processing industry, especially for the production of cutlery. Sanjo is an industrial city with several industrial complexes.

\subsection{What is Sanjo-Ika-Gassen}

Sanjo-Ika-Gassen is held on the first Saturday and Sunday of every June at the Igarashi River flowing through the city. This kite battle is contested by two opposing forces, with participant teams called "Kumi" separated into two forces. Giant kites are managed and flown by each Kumi team. Participant Kumi teams compete for points gained when cutting the flying line of opponents' kites by hitching their lines in the air or knocking them to the ground.

The kite used in this kite battle has a unique hexagonal shape which is specific in Sanjo City. The kite has a characteristic of easy portability because its bone (fram) can be pulled out, which enables the kite to be rolled. Therefore, the kites of Sanjo-Ika-Gassen are called Rokkaku-Ika (hexagonal kite), Maki-Ika (rolled-up kite), and Rokkaku-Maki-Ika (rolled-up hexagon kite) $)^{3}$. It is introduced as "the Sanjo
Rokkaku" in several international websites on kites ${ }^{4}$.

Although a kite is called tako in current "Tokyo" style Japanese expression, ika is used for a kite in this district in keeping with old times. Thus the kite battle is called "Ika-Gassen" and not Tako-Gassen.

\subsection{History of Ika-Gassen (the Great Kite Battle)}

Kite have been used for a long time in Sanjo City. There is a theory that the kite originated in the turbulent period around sixteenth century, when it was used as a beacon ${ }^{5}$. However, kite battles started during the Edo era. In 1649, the manor house of Murakami Domain was built in Sanjo City. The children of officials attending the manor house started to fly kites on the day of the Iris Festival (May 5). Watching their kites flying, children of townspeople challenged them from a long distance by flying their kites and trying to cut the flying lines of others' kites. This is the beginning of the kite battle, which became popular among adults as well. It is said that the battle arrangement of officials versus townspeople turned to a kite battle among communities of town blocks ${ }^{6}$.

After the Meiji Restoration, kite battles between officials and townspeople disappeared because the manor house had been abolished, while the kite battles among townspeople continued to exist. Nevertheless, a massive conflagration devastated the town in 1880 and restoration took many years. Combined with the fact that electric wires were installed around the city, which could be an obstacle to the kite flying, and that railroad construction laborers who were participating in the event one year committed an assault, kite battles were prohibited in the town. In consequence, kite battles declined and became nearly obsolete in 1900 . However, students attending school in town became interested in kite battles and resurrected the event in 1909. Moreover, the "Sanjo Town Ika Society" was established in 1911 to decide the list of rules, to choose the place for the battle, and to manage the kite battles thereafter ${ }^{7}$.

Records on the battles in the early twentieth century have not been located yet, while records of

3 In this study, "a kite" means a hexagonal kite hereafter. The word "hexagonal kite" will be used when distinguishing it from other shaped kites.

$4 \mathrm{http}: / /$ www.xs4all.nl/ pdj/rok.htm, http://www.kitebuilder.com/techsheets/sanjo.htm etc.

5 Tamura, O., 1992, Patriotic Pride, MBC21 (in Japanese) p.29

6 Ibid. pp.32-32 and a brochure on Sanjo-Ika Gassen

7 Kite Battle in Echigo, Hokuetsu-shimpo (newspaper) Jan. 1, 1912 


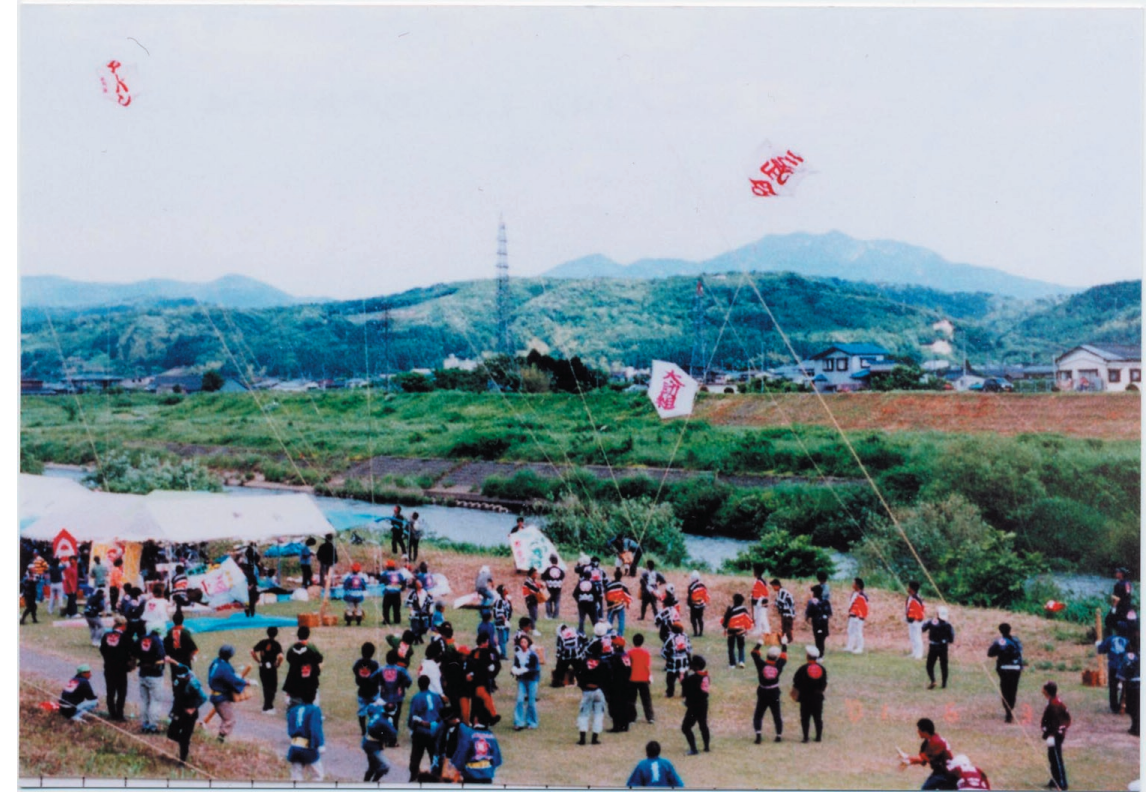

Figure 2 Sanjo-Ika-Gassen (a picture of the battle, photographed by Ikkai)

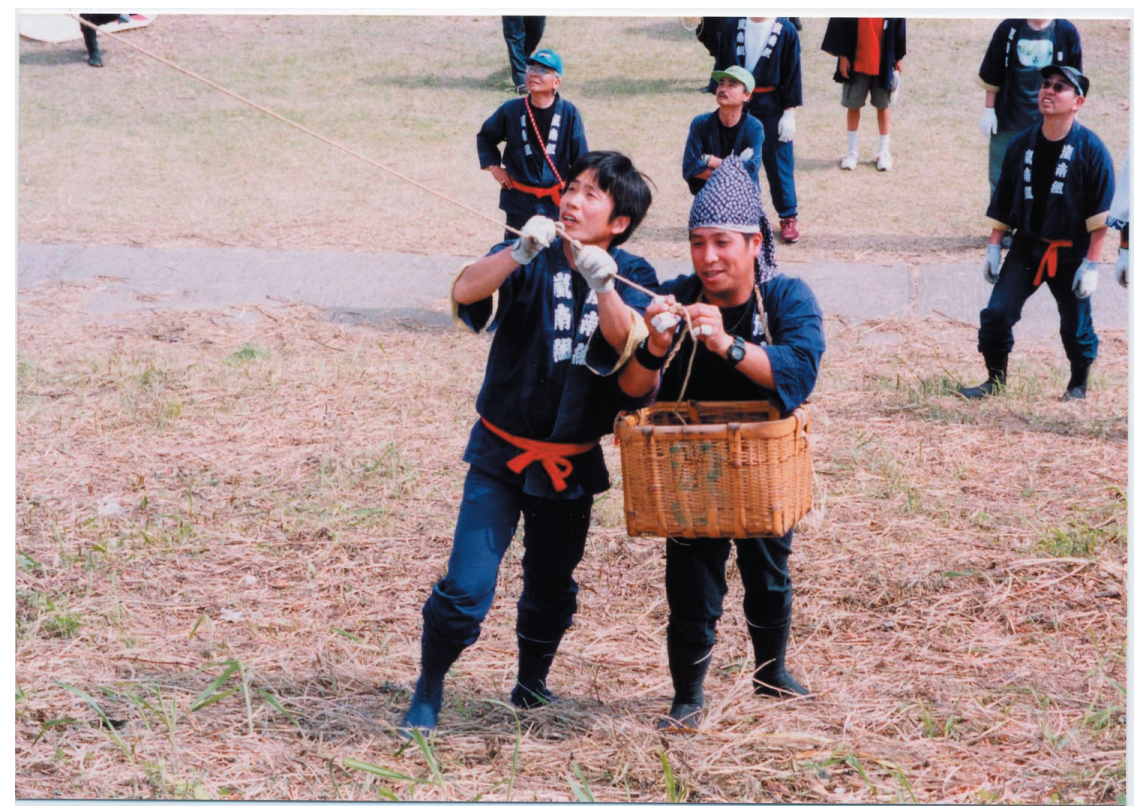

Figure 3 age-shi and kago-mochi, photographed by Ikkai

the champions have been kept from 1930 onward. Although there was no record through the World War II, kite battles have been held every year since 1952, except in 1966 and in 1967 due to participant shortages and in 1978 due to rain ${ }^{8}$. At present, management of the kite battles is assumed by the "Sanjo Kite Association" (the association, hereafter) composed of representatives of each Kumi team. Records on the association are scarce and only the fact that it was established about twenty years ago is clear. The connection between the association and the above-mentioned "Sanjo Town Ika Society" remains to be elucidated.

\subsection{The game}

In Sanjo-Ika-Gassen participants compete for points gained when cutting the flying line of opponents' kites by hitching the lines in the air or knocking them down to the ground. Matches are played by two forces of Kumi teams separated into opposing two forces, and two Kumi teams representing either force face each other to battle. Matches between individual players are not performed.

Each participant Kumi team is allocated to two forces by drawing lots. Participants fly kites from either upriver or downriver side across the umpire boundary line in the battle fields, and the sides are changed each day. An age-shi (flyer) who flies a kite and a kago-mochi (basket carrier) who carries a basket for the flying lines participate in the match. Each Kumi team is allowed to fly one kite. The size of a kite is more than 30 mai-do (one $d o$ (sheet) is the size of a typical sheet of Japanese writing paper for a total of $2.17 \mathrm{~m}$ in height $\times 1.74 \mathrm{~m}$ in width) and a name or a graphic design representing each team is drawn on it as a rule. The sheets of paper are glued together and the number of sheets shows the size of a kite. A "standby field" is set behind each battle field, where a spare kite can be ready to battle, flying adjusted to the

8 The Sanjo kite association keeps records of past champions. According to the records, only "suspended" was written in 1966 and 1967 and attached from 1968 to 1975 is the proviso "the number of participating Kumi teams were so small that they could not be separated into two forces." 


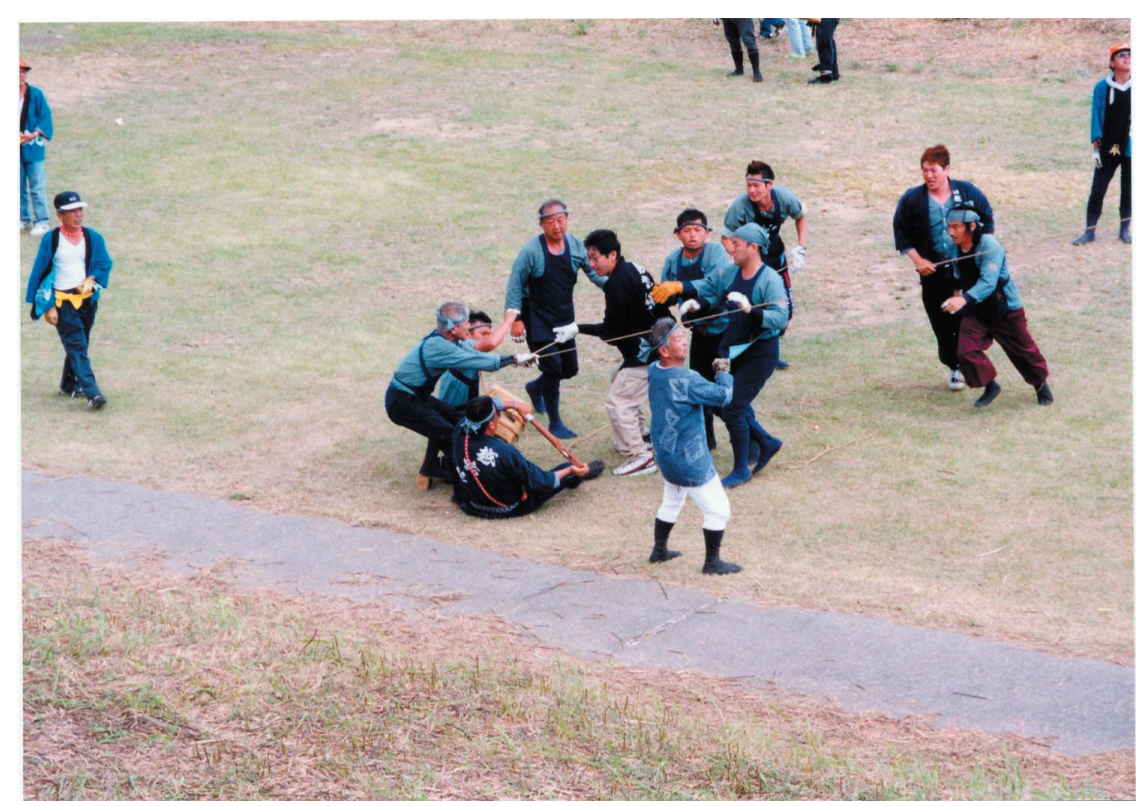

Figure 4 Tugging the flying line of kite, photographed by Ikkai

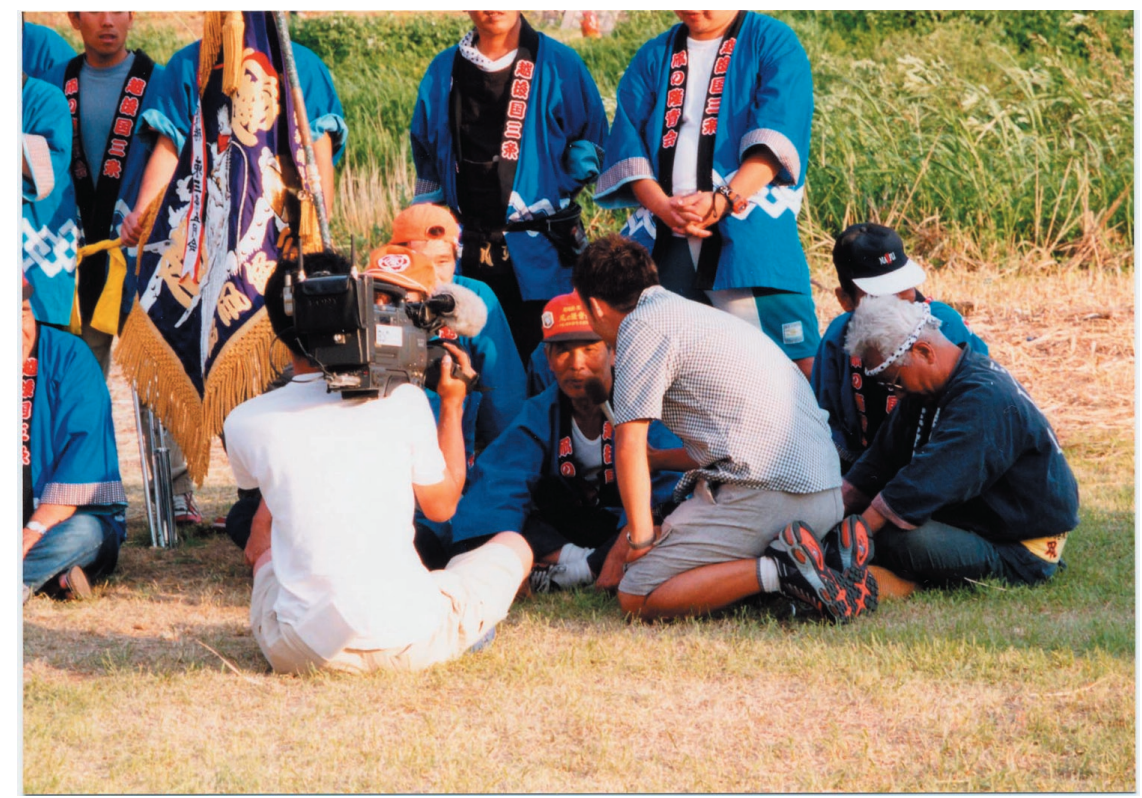

Figure 5 Television interview with the winning team, photographed by Ikkai wrap-around jackets) specified by each Kumi team.

When the flying line of either side is cut or either kite drops to the ground, the battle ends and the winning team gains points. If the flying line is cut spectacularly up in the air, the team earns 5 points, while 3 points are gained for just cutting in the air and 1 point for grounding the opponent's kite or for hooking the opponent's kite into the friendly standby field. The looser gets zero points.

The kite battle continues for two days and the ranking is decided based on the total points of each Kumi team earned during the two days. The champion, the runner-up and the third-prize winner of both forces are awarded with a flag, a certificate of merit, and a great kite (only for the champion). Of the two forces, the champion Kumi team which gained the most points, is awarded with a flag printed with a dragon and the other champion Kumi team with a flag printed with a tiger. People who show outstanding performance and technique are honored with the technique award, the outstanding performance award and the fighting-spirit award. One highly excellent person is awarded with the best technique prize. ${ }^{9}$ direction of the wind.

When the kite entangled with the opponent kite, a participant declares the beginning of battle to the umpire in the center of battle field. As the battle begins, the other members join the battle as well as age-shi and kago-mochi to tug the string in order to cut the opponent's line. Although there is no limitation on the number of members, members are required to wear happi coats (traditional Japanese

\section{Transition of Sanjo-Ika-Gassen}

\subsection{Flying line}

Traditionally there had been no prohibition on the flying line except a ban on the use of a hemp string processed with metal objects applyied or with glass powder. However, since 2001 the flying line has been limited to strings of Manila hemp or

9 These rules are collected as the "Rules and regulations of Sanjo-Ika Gassen" (issued by the Sanjo kite association). 
hemp without bleaching process. This revision was intended to prevent the decrease of spectacular battles because the bleached string increases the intensity and is difficult to cut in the air.

There is no regulation as to the diameter or the length of flying line. String of $3 \mathrm{~mm}-13 \mathrm{~mm}$ in diameter is frequently used and applied appropriately according to the size of the kite and strength of the wind.

Wooden line cutters called wani or hanao-dome are allowed, except those with metal parts inside, which were banned in 2001 .

\subsection{Kumi team}

As mentioned before, participants compete in teams called Kumi but not as individuals ${ }^{10}$. This is because originally the battles were fought among town blocks. Presently Kumi teams are not restricted to town blocks but to kite lovers in the city. Each Kumi team has some qualifying standards concerning its members, while the association has no common standards concerning participants. Although basically most Kumi teams consist of residents in Sanjo City, there is a team such as Sanjo-Komachi-kai (see below) which accepts out-of-town participants if they meet this Kumi team's standards.

In 1912, a newspaper article reported 28 names of Kumi teams which participated in the event ${ }^{11}$, while a document of 1954 mentioned nine Kumi teams. It is unknown if all of the participating teams were covered or not. Moreover, one record says that a battle between two forces could not be held because the number of participant Kumi teams was so small. A considerable number of Kumi teams seem to have been abolished or recessed at that time. There are few documents of those days in the association and the number of remaining Kumi teams was uncertain. In recent years, the number of participating Kumi teams has remained in the low-20s to mid-20s.

There was an all-comers team called Ryuoh-gumi consisting of citizens and tourists until 2000. Due to technical or safety problems such as a kite falling somewhere unpredictably or people getting abrasions or burns from touching a rapidly moving flying line, the all-comers team was prohibited from participation in 2001. Since 2001 a free-kiteflying space has been set outside of the battle field to experience kiteflying, which enables outsiders to have a chance to participate in the event.

\subsection{Form of the event}

The method of separating participant Kumi teams into two opposing forces has been provided in the list of clauses which was agreed in the "Sanjo Town Ika Society" in $1911^{12}$. Thus, it is assumed that the present form of the event follows this. Although Sanjo-Komachi-kai whose participants are all women, and Tama-tako-ren which has a long relationship with this event and is the only Kumi team whose members are from outside of Sanjo City, were once given special treatment to retain the same battle field for two days, since 2001 these teams have been treated in the same way as the other Kumi teams to change the battle field by day.

Furthermore, since 1955 the champion's record has carried the record of the overall champion and the Kumi team with the highest score. This suggests that the victory was decided by the scorekeeping from 1955 at the latest. The "Rules and regulations of Sanjo-Ika-Gassen" appeared in the officially codified form in April 1995 as far as the present writer knows. Today, the event complies with these rules and regulations.

\subsection{Management}

The "Sanjo Kite Association", which mainly consists of representatives of each Kumi team, manages Sanjo-Ika-Gassen. The association is an organization composed of about 30 members including those who represent each Kumi team and those recommended by the president (mainly former directors of the association), and some advisers. In this system, the members recommended by

\footnotetext{
10 Participants in the 2004 match were the following 21 Kumi teams: Asahi-gumi, Higashisanjo-Satsuki-kai, Ichinomon-Kiyomasa-gumi, Kamimachi-gumi, Kensei-kai, Kenshin-gumi, Maromi-kai, Nishiuradate-Fujin-gumi, Ohmachi-gumi-Kagekiyo, Raijin-gumi, Ran’ nan-gumi, Ryusei-kai, Sanbu-kai, Sanjo-Komachi-kai, Sanjo-Koshiji-gumi, Sanryu-kai, Seiyu-kai, Shiyakusho-Ika-kurabu (City office kite club), Tajima-gumi, Tako-no-Fuji-gumi, Tama-tako-ren (alphabetical order)

11 Kite Battle in Echigo, Hokuetsu-shimpo (newspaper) Jan. 1, 1912.

12 Ibid.
} 
the president will remain in the association when a representative of a Kumi team changes so that the replacement would not pose a problem in the management until the replacement learns the job.

The association system has been running for 20 years. In former days, the operation of the kite battle was conducted voluntarily by representatives of each Kumi team. In practice, they met together three or four months before the kite battle, and dissolved themselves closing an account after the battle. This pattern of gathering and dissolution was repeated without a permanent governing body. After the low ebb from the late 1960's to 1970 's, with a move to encourage activities including not only the kite battle but also other events and exchanges with outside groups, the need for a permanent governing body increased and the association was established as a result.

However, documents and records on the association are scarce. The year of establishment is only comprehended to be approximately 1980, about 20 years ago as of 2005. The association is said to have being completed as an organization during these years. The total number of association members has just started to be counted in round numbers by collecting data after 2000. ${ }^{13}$

Representatives of each Kumi team are called to hold a convention before the kite battle. Participant Kumi teams are separated into two forces in the convention. The representatives work not only as a connection between the association and each team, but they assist the management of the kite battle in maintaining the field before the battle, supporting the umpire on the day of the battle (reporting when lines are entangled and a battle starts).

Although the sponsors of the kite battle are Sanjo City and the association, the support of Sanjo City remains restricted to the role of $\mathrm{PR}$ activities and financial support including featuring the event and printing photographs in information publications and city brochures, as well as offering 300 thousand yen per year as an "activity contribution". However, since the city considers the kite battle as a tourism resource ${ }^{14}$, it might be possible for the city to promote the transition such as making rules easily understood by tourists and unifying the attire of participants in future. In the meantime, since the historical process of the kite battle which was an entertainment among town blocks should be respected, the city wavers on how best to promote tourism.

\section{Some considerations}

\subsection{Awareness as "the birthplace of rolled-up hexagonal kite"}

Sanjo City advocates that it is the birthplace of rolled-up hexagonal kite in its city tourism brochures and the Ika-Gassen brocures as well as in its website and other publications. The association sent a letter declaring that Sanjo City is "the birthplace of the Japanese rolled-up hexagonal kite" to a specialized magazine in the United States in $1988^{15}$. The kite shops started to make the new kites as artifacts made specially in Sanjo City, including souvenir kites and ornament kites in frames, as well as great kites for battle and toy kites. Some confectionery shops in the city sell kite-shaped hexagonal sweets as regional products.

As mentioned in Chapter II, the rule on a flying lines used in the kite battle was changed in 2001. The kite itself remains the same traditional hexagonal shape. In contrast, rectangular kites as well as hexagonal kites are mainly used at the great kite battle held in neighboring Shirone City. In Mitsuke City, which is also in the area, the great kite battle is held with only hexagonal kites, but they do not call their city the "birthplace" of hexagonal kites.

The great kite used in the Sanjo-Ika-Gassen is made of Japanese paper, bamboo and cotton yarn through a traditional manufacturing process. Chemical materials such as plastic are not used. Each Kumi group places an order with a kite shop for the kite in general, because the kite is so large that special techniques are necessary to make the kite and to adjust its bones. Although there were once more than a dozen kite shops in Sanjo City, only two shops remain at present. The fact that almost the whole

\footnotetext{
13 The regular members were about 200 and affiliated Kumi teams were about 30 at most according to the data in 2000.

14 he kite battle is not designated as one of the intangible folk cultural properties of the nation nor the Prefecture nor the City. Therefore, the Commerce and Industry division of the Economy Department, which conducts tourism activities, has the charge of the kite battle and not the Education Committee, which conduct various activities related to cultural properties, in the Sanjo City office.

15 Refer to Tamura, O., 1992, (in Japanese) pp.60-61 for detailed matters.
} 
manufacturing process must be worked by hand and only a part of bone processing could be mechanized seems somewhat to have caused the decline in the number of shops.

With this trend, the association positions succession planning as an important issue. As a part of efforts to tackle the issue, it plans to hold activities including kite battles for younger age-shi (flyers) every autumn, kite flying lesson on the second Sunday of each month as "the day of kites", and sending staff from the association to elementary and junior high schools in the city to instruct in making kites and kiteflying when schools take up the kite as educational material in their integrated study periods.

The city activities, done in conunction with the association and local people, show that Sanjo City residents regard the hexagonal kite and the kite battle as "representing their community" and feel the challenge to protect and pass on their culture as the birthplace of rolled-up hexagonal kites. In order to be distinguished from neighboring kite battles, the exclusive use of hexagon kites which are made through the traditional manufacturing processes and the appeal of being the birthplace of hexagonal kites are assumed to be effective and necessary.

\subsection{The kite battle as tourism resource}

Sanjo City regards the kite battle as one of its most important tourism resources, while it does not encourage positively the promotion of tourism in consideration of opinions of participants and the association. Scenes from the kite battle are taped by a local TV station and broadcast later as a digest program. The kite battles of neighboring Shirone City and Mitsuke City have also been broadcast before, but only the battle in Sanjo is still broadcast today because the other cities lost sponsors.

In the 2001 activity plan of the association ${ }^{16}, " 1000$ participants in the kite battle plan", "the interesting and amusing kite battle", "maintenance and enhancement of the battle field", and "improvement in technique and succession plan" are set as major guidelines. Each guideline concerns not only participants but also the existence of tourists. The section of "maintenance and enhancement of the battle field" in particular proposes to set "a festival field where spectators can enjoy all day long". There also have been local product shops and food stands, and replacing the Ryuoh-gumi which used to be a competing team allowing all comers, the "free kiteflying space" instead allows people from outside to experience kiteflying.

Furthermore, a concern for the decrease of spectacular air battles due to using shred-resistant strings made the rule on kite flying lines stricter. Some participants of the kite battle think that the highlight of the Sanjo-Ika-Gassen is the manipulation of kites in the air, and attach importance to the fact that they neither fly a kite with flying lines entangled in advance nor do they allow ji-garame ${ }^{17}$, in which entangled lines are tugged by each other on the ground without flying in the air. This attitude shows their willingness to protect not only the characteristics of kite battles but also the attractiveness of kiteflying as a spectacle sport.

Thus, the phenomena associated with kite battles have brought wide attention as well as the improvement of techniques related to the kite battle. After the abolition of Ryuoh-gumi, in particular, the fact that the event provided a recreational kiteflying space seems to be intended to keep the feature of participatory attraction.

\section{Conclusion}

The traditions and transitions of the Sanjo-IkaGassen can be stated as "pride in being the birthplace of the roll-up hexagonal kite" and "working to develop kite battles as a tourism resource". Since kite battles started, there has been considerable transition including changes from the competition among town blocks to competition among Kumi teams, and from entertainment of the townspeople to tourist-conscious participatory attraction.

However, not a few problems remain to be tackled, including the decline of kite shops which produce kites, and training of successors in order to activate and expand kite battles. The Sanjo-Ika-Gassen is one example of Japanese ethnic sports trying to ensure compatibility between tradition and transition in promoting tourism with the appeal of uniqueness.

16 Offered by the Sanjo kite association

17 Some informants refer to the kite battle in Mitsuke City as one where ji-garame is allowed probably in order to exhibit the difference between it and others. 
Ikkai, C

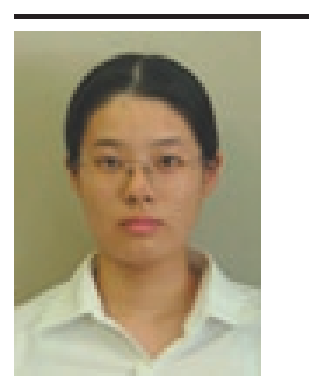

\section{Name:}

Chie Ikkai

\section{Affiliation:}

Research associate, Faculty of Sport Sciences, Waseda University

\section{Address:}

2-579-15 Mikajima, Tokorozawa, Saitama 359-1192 Japan

Brief Biographical History:

2002 Revised master's degree at Waseda University

2002-2005 Docter's course, Graduate school of Human sciences, Waseda University

2006- Research associate, Faculty of Sport Sciences, Waseda University

\section{Main Works:}

- "Women's Sumo show of the Edo period", Japan Journal of Sport Anthropology, Vol.4, 2002, pp.17-40

- "Women's Sumo Wrestling in Japan", International Journal of Sport and Health Science, Vol.1 No.1, 2003, pp.178-181

Membership in Learned Societies:

- Japan Society of Physical education, Health and Sport Scienses

- Japan Society of Sport Anthropology 